\title{
The Role of Routine Diagnostic Radioiodine Whole-Body Scintigraphy in Patients with High-Risk Differentiated Thyroid Cancer
}

\author{
Siegrid G. de Meer ${ }^{1}$, Menno R. Vriens ${ }^{1}$, Pierre M. Zelissen ${ }^{2}$, Inne H. Borel Rinkes ${ }^{1}$, and Bart de Keizer ${ }^{3}$ \\ ${ }^{I}$ Department of Surgery, University Medical Center Utrecht, Utrecht, The Netherlands; ${ }^{2}$ Department of Endocrinology, University \\ Medical Center Utrecht, Utrecht, The Netherlands; and ${ }^{3}$ Department of Nuclear Medicine, University Medical Center Utrecht, \\ Utrecht, The Netherlands
}

Follow-up diagnostic radioiodine whole-body scintigraphy (DxWBS) is still advised for high-risk patients with differentiated thyroid cancer. The aim of this study was to evaluate the additional value of DxWBS to stimulated thyroglobulin measurement in high-risk patients. Methods: The results of DxWBS and thyroglobulin measurements performed 6-12 mo after surgery and radioiodine thyroid remnant ablation in patients with differentiated thyroid cancer were retrospectively evaluated for 112 patients with high-risk features for recurrence (R3/T4 and N1). Results: One patient had an undetectable thyroglobulin level, with DxWBS results suggestive of cervical recurrence. DxWBS was found to be false-positive. Of the patients with detectable thyroglobulin levels, the DxWBS results were negative in 65 and positive in only 8 . The 6 patients positive for thyroglobulin antibody had negative DxWBS results. The remaining patients had an undetectable thyroglobulin level and negative DxWBS results. Conclusion: Because undetectable stimulated thyroglobulin levels have a negative predictive value of $100 \%$, DxWBS offers no information additional to recombinant human thyroid-stimulating hormone-stimulated thyroglobulin measurements in patients with high-risk differentiated thyroid cancer.

Key Words: endocrinology; oncology; diagnostic value; diagnostic whole-body scintigraphy; well-differentiated thyroid cancer

J Nucl Med 2011; 52:56-59

DOI: 10.2967/jnumed.110.080697

\section{D} ifferentiated thyroid carcinoma is a common malignancy with excellent survival rates $(1,2)$. Lifelong followup of patients is important because recurrences regularly occur (3-6).

Traditionally, follow-up consisted of periodic assessment of thyroglobulin and thyroglobulin antibody levels and performance of thyroid-stimulating hormone (TSH)-stimulated

Received Jun. 29, 2010; revision accepted Sep. 27, 2010.

For correspondence or reprints contact: Siegrid G. de Meer, Heidelberglaan 100, 3508 GA Utrecht, The Netherlands.

E-mail: s.g.a.demeer-2@umcutrecht.nl

COPYRIGHT (c) 2010 by the Society of Nuclear Medicine, Inc. thyroglobulin measurement simultaneous with diagnostic radioiodine whole-body scintigraphy (DxWBS) 6-12 mo after initial treatment with near-total thyroidectomy and ${ }^{131}$ I remnant ablation.

For low-risk patients, however, the use of follow-up DxWBS is no longer recommended by either the American or the European guidelines $(3,7)$.

For high-risk patients, the value added by DxWBS to TSH-stimulated thyroglobulin measurement is largely unclear, because no studies evaluating this value have been performed in a large group of well-defined high-risk patients.

The aim of our study was to determine whether routine DxWBS performed 6-12 mo after initial therapy offers information additional to that provided by TSH-stimulated thyroglobulin measurement during the first year of followup of differentiated thyroid carcinoma patients with predetermined high-risk features.

\section{MATERIALS AND METHODS}

From January 1998 until January 2009, all consecutive patients who had undergone surgery for thyroid carcinoma and had been referred to the Department of Nuclear Medicine for ${ }^{131} \mathrm{I}$ ablation were retrospectively studied. Patient characteristics and follow-up parameters, such as laboratory measurements and the results of DxWBS, were recorded. In addition, tumor characteristics, preoperative and postoperative staging, and the results of surgery were registered. Follow-up data such as disease recurrence, duration of follow-up, and laboratory measurements (thyroglobulin and thyroglobulin antibody) were also considered. DxWBS 1 y after initial treatment was judged positive if uptake outside regions of physiologic uptake - such as the oral, nasal, or gastric mucosa; the salivary glands; or the urogenital region-or uptake classified as thyroid remnant was observed.

\section{High- Versus Low-Risk Patients}

The American and European guidelines differ in the definition of high- versus low-risk patients. In addition, the American guideline identifies intermediate-risk patients $(3,7)$.

In our study, we used the American Joint Committee on Cancer (AJCC) TNM version 7 classification in determining the T stage of the various tumors $(8)$.

For this study, we defined high-risk patients as patients with T3 or T4 tumors or positive cervical lymph nodes (N1). We did not 
include age as a predictor of low- or high-risk disease, because the treatment protocol is independent of age. This definition is in concordance with the European guideline. Patients with distant metastasis (M1) were excluded from analysis.

\section{Diagnostic Whole-Body Scintigraphy}

Until December 2004, all patients referred for DxWBS 6-12 mo after initial therapy were withdrawn from LT4 medication 4 wk before administration of $370 \mathrm{MBq}$ of ${ }^{131} \mathrm{I}$. From January 2005 onward, patients received intramuscular injections of $0.9 \mathrm{mg}$ of recombinant human TSH on 2 consecutive days followed by administration of $370 \mathrm{MBq}$ of ${ }^{131} \mathrm{I}$ on day 3, obviating LT4 withdrawal. Blood samples were taken to measure thyroglobulin levels and thyroglobulin antibody on days 3 and 5. The serum TSH level was measured on day 3. One week after administration of ${ }^{131}$ I, DxWBS was performed with a dual-head $\gamma$-camera (MCD; Philips) fitted with high-energy collimators. Ten-minute spot views on a $256 \times$ 256 matrix were obtained with a $15 \%$ energy window centered on a 364-keV photopeak of the head, neck, thorax, and abdomen.

\section{Laboratory Analysis}

Thyroglobulin and thyroglobulin antibody levels were measured using the DYNOtest thyroglobulin-pluS (Brahms Diagnostica $\mathrm{GmBH})$. The functional sensitivity, defined as the lowest thyroglobulin level that can be measured with a variation of less than $20 \%$, for this assay is $0.2 \mathrm{ng} / \mathrm{mL}$. TSH levels were measured simultaneously and exceeded $20 \mathrm{mU} / \mathrm{L}$ in all patients.

All thyroglobulin and thyroglobulin antibody levels indicated in the text or tables are TSH-stimulated measurements, either by LT4 withdrawal or recombinant human TSH injection.

\section{Statistical Analysis}

Statistical analysis was performed using SPSS 13.0. All demographic data are shown as mean values \pm SD unless indicated otherwise. For statistical analysis, we used $\chi^{2}$ and $t$ tests where appropriate. $P$ values less than 0.05 were considered statistically significant.

\section{RESULTS}

\section{Patient Characteristics}

From January 1998 until January 2009, 402 patients were treated with ${ }^{131} \mathrm{I}$ ablation therapy after resection of differentiated thyroid carcinoma in the University Medical Center Utrecht, The Netherlands. Two hundred eleven patients were excluded from analysis because they were classified as lowrisk patients on the basis of tumor size and lymph node status (T1/T2N0); 20 of the remaining high-risk patients had metastatic disease at the time of diagnosis and were therefore excluded. Another 59 patients were not included in the final analyses either because information about thyroglobulin level or DxWBS was missing $(n=56)$ or because they were treated with a blind therapeutic dose and posttherapeutic scintigraphy was performed $(n=3)$.

As a result, 112 high-risk patients remained for final analysis. Most of these patients were female (70\% vs. $30 \%$ ). The median age was 48 y (range, 20-83 y) (Table 1).

\section{Tumor Characteristics}

Median tumor size in these patients was $30 \mathrm{~mm}( \pm 20$ $\mathrm{mm}$, with a range of 3-90 $\mathrm{mm})$. Most patients were treated for papillary carcinoma $81 \%(n=91)$ (Table 1$)$.
TABLE 1

Patient and Tumor Characteristics of 112 High-Risk Patients with Well-Differentiated Thyroid Carcinoma

\begin{tabular}{|c|c|}
\hline Characteristic & Result \\
\hline \multicolumn{2}{|l|}{$\operatorname{Sex}(n)$} \\
\hline Male & $35(31 \%)$ \\
\hline Female & $77(69 \%)$ \\
\hline Median age \pm SD (y) & $48 \pm 16$ \\
\hline Median tumor size $\pm \mathrm{SD}(\mathrm{mm})$ & $30 \pm 20$ \\
\hline \multicolumn{2}{|l|}{ Tumor histology $(n)$} \\
\hline Papillary & $91(81 \%)$ \\
\hline Follicular & $21(19 \%)$ \\
\hline Hürthle cell & $8(7 \%)$ \\
\hline \multicolumn{2}{|l|}{${ }^{131}$ I ablation dosage $(n)$} \\
\hline $3,700 \mathrm{MBq}$ & $40(36 \%)$ \\
\hline $5,550 \mathrm{MBq}$ & $63(56 \%)$ \\
\hline $7,400 \mathrm{MBq}$ & $9(8 \%)$ \\
\hline \multicolumn{2}{|c|}{ TNM stage at time of diagnosis $(n)$} \\
\hline 1 & $48(43 \%)$ \\
\hline 2 & $6(5 \%)$ \\
\hline 3 & $24(21 \%)$ \\
\hline 4 & $26(23 \%)$ \\
\hline Missing & $8(7 \%)$ \\
\hline \multicolumn{2}{|l|}{$\mathrm{T}$ and $\mathrm{N}$ stage $(n)$} \\
\hline T1N1 & 22 \\
\hline $\mathrm{T} 2 \mathrm{~N} 1$ & 23 \\
\hline T3NO & 31 \\
\hline T4N0 & 14 \\
\hline T3N1 & 10 \\
\hline $\mathrm{T} 4 \mathrm{~N} 1$ & 3 \\
\hline TxN1 & 9 \\
\hline
\end{tabular}

\section{TNM Stage}

TNM stage according to the 2010 TNM criteria at the time of diagnosis was stage I in most patients (43\%). In 8 patients $(7 \%)$, the TNM stage was unknown because of missing information about the primary tumor size (Table 1). Specified information on the $\mathrm{T}$ and $\mathrm{N}$ stages of the tumor is also shown in Table 1.

\section{DxWBS and Thyroglobulin Measurement}

The results are summarized in Table 2.

Most patients had a thyroglobulin value above the lower detection limit of $0.2 \mathrm{ng} / \mathrm{mL}(66 \%)$. Only 8 patients had a thyroglobulin value above $0.2 \mathrm{ng} / \mathrm{mL}$ in combination with positive DxWBS results.

All these patients were diagnosed with disease recurrence. In 6 patients, only neck recurrence was observed. The other 2 patients were diagnosed with a distant metastasis to the skull (1 patient) or to the lung and brain (1 patient).

In 31 patients $(30 \%)$, thyroglobulin measurements were below $0.2 \mathrm{ng} / \mathrm{mL}$, no thyroglobulin antibody was found, and DxWBS showed no signs of recurrent or metastatic disease. Six patients $(5 \%)$ had undetectable thyroglobulin measurements in the presence of thyroglobulin antibody. None of these patients had DxWBS results suggestive of cervical node metastases.

Of the patients with an undetectable thyroglobulin level and no detectable thyroglobulin antibody, 1 had DxWBS 
TABLE 2

Results of DxWBS 6-12 Months After Initial Therapy Combined with Thyroglobulin Level Measurements of 112 High-Risk Patients

\begin{tabular}{|c|c|c|c|c|}
\hline \multirow[b]{2}{*}{$\begin{array}{c}\text { DxWBS } \\
\text { result }\end{array}$} & \multicolumn{3}{|c|}{ Thyroglobulin } & \multirow[b]{2}{*}{ Total } \\
\hline & $<0.2 \mathrm{ng} / \mathrm{mL}$ & $>0.2 \mathrm{ng} / \mathrm{mL}$ & $\begin{array}{l}\quad<0.2 \mathrm{ng} / \mathrm{mL} \text {, } \\
\text { but thyroglobulin } \\
\text { antibody present }\end{array}$ & \\
\hline Negative & 32 (29\%) & 65 (58\%) & $6(5 \%)$ & 103 \\
\hline Positive & $1(1 \%)$ & $8(7 \%)$ & $0(0 \%)$ & 9 \\
\hline Total & 33 & 73 & 6 & 112 \\
\hline
\end{tabular}

findings suggestive of cervical node metastases. Additional imaging using neck ultrasound, ${ }^{18} \mathrm{~F}-\mathrm{FDG}$ PET, and MRI found no evidence of cervical recurrence. DxWBS performed 1 y later showed no uptake, and thyroglobulin levels remained undetectable, without the presence of thyroglobulin antibody.

The negative predictive value of stimulated thyroglobulin levels less than $0.2 \mathrm{ng} / \mathrm{mL}$ for disease recurrence in our group was therefore $100 \%$.

\section{DISCUSSION}

The European and the American guidelines have different definitions of high-risk differentiated thyroid cancer, and neither guideline stages into groups according to the AJCC cancer staging manual (8). The authors of the American guideline introduce a 3-level stratification system because the AJCC cancer staging manual was developed to predict death, not recurrence (9). The authors of the European guideline do not state why they choose to introduce their own definition of high-risk differentiated thyroid cancer.

The American and European guidelines do not give clear advice on the use of DxWBS. The recently published American guideline states that DxWBS may be of value in the follow-up of high- or intermediate-risk patients. This recommendation is based on expert opinion and does not specifically say when or when not to perform DxWBS (3). The European consensus statement states that DxWBS is indicated by some authors in the follow-up of high-risk patients or when postablation scintigraphy is poorly informative or discloses suggestive uptake $(10,11)$. Routine DxWBS is advised for patients positive for thyroglobulin antibody (7). Our study indicated that routine DxWBS added no diagnostic value to stimulated thyroglobulin level measurement in a large population of patients with highrisk differentiated thyroid carcinoma.

The literature about this subject is limited, and most studies have evaluated low- and high-risk patients together. Only the study by Verburg et al. analyzed high-risk patients separately, but the high-risk group contained only 44 patients and lacked a clear formulation of high-risk criteria. Still, the authors concluded that routine DxWBS might be omitted in high-risk patients just as in low-risk patients (12). Other studies have found that in their study popula- tion, which also included high-risk patients, DxWBS had no value additional to that provided by stimulated thyroglobulin measurement (12-17).

Robbins et al. strongly advocate the routine performance of DxWBS in the follow-up of all differentiated thyroid carcinoma patients. The authors concluded that thyroglobulin measurement alone is insufficient to detect all recurrences or metastases and that DxWBS detected the recurrences or metastases missed by thyroglobulin measurement, therefore complementing the thyroglobulin measurement (18).

DxWBS can have a role in patients with thyroglobulin antibody present. Because of thyroglobulin antibody interference in immunometric tests, thyroglobulin levels are unreliable in the presence of these antibodies (19).

In patients with detectable thyroglobulin $(>2 \mathrm{ng} / \mathrm{mL})$, further diagnostic imaging is required. In these patients, DxWBS is one of the tools that can be used to detect recurrent or metastatic disease. Other options include blind therapeutic activities, which are the administration of ${ }^{131} \mathrm{I}$ without previous visualization of the anatomic substrate. Posttherapeutic scans are more sensitive, but DxWBS delivers a far lower radiation burden to the patient. Approximately $40 \%$ of posttherapeutic scans are negative and will not reveal thyroglobulin-producing lesions (20). Other imaging modalities, such as ${ }^{18} \mathrm{~F}-\mathrm{FDG}$ PET, ${ }^{124} \mathrm{I}$ PET, CT, and MRI, can be used in an attempt to localize recurrent or metastatic differentiated thyroid carcinoma in patients in whom disease is suspected on the basis of the thyroglobulin level.

\section{CONCLUSION}

There is no benefit of the routine use of follow-up DxWBS in high-risk patients, and we recommend that it be omitted in all differentiated thyroid cancer patients who are not positive for thyroglobulin antibody, regardless of initial high-risk staging.

\section{REFERENCES}

1. Sampson E, Brierley JD, Le LW, Rotstein L, Tsang RW. Clinical management and outcome of papillary and follicular (differentiated) thyroid cancer presenting with distant metastasis at diagnosis. Cancer. 2007;110:1451-1456.

2. Sciuto R, Romano L, Rea S, Marandino F, Sperduti I, Maini CL. Natural history and clinical outcome of differentiated thyroid carcinoma: a retrospective analysis of 1503 patients treated at a single institution. Ann Oncol. 2009;20:1728-1735.

3. Cooper DS, Doherty GM, Haugen BR, et al. Revised American Thyroid Association management guidelines for patients with thyroid nodules and differentiated thyroid cancer. Thyroid. 2009;19:1167-1214.

4. Mazzaferri EL, Jhiang SM. Long-term impact of initial surgical and medical therapy on papillary and follicular thyroid cancer. Am J Med. 1994;97:418-428.

5. Pacini F, Cetani F, Miccoli P, et al. Outcome of 309 patients with metastatic differentiated thyroid carcinoma treated with radioiodine. World J Surg. 1994;18:600-604.

6. Mazzaferri EL, Kloos RT. Clinical review 128: current approaches to primary therapy for papillary and follicular thyroid cancer. J Clin Endocrinol Metab. 2001;86:1447-1463.

7. Pacini F, Schlumberger M, Dralle H, Elisei R, Smit JW, Wiersinga W. European consensus for the management of patients with differentiated thyroid carcinoma of the follicular epithelium. Eur J Endocrinol. 2006;154:787-803.

8. Edge SB, Byrd DR, Compton CC, Fritz AG, Greene FL, Trotti A, eds. AJCC Cancer Staging Manual. 7th ed. New York, NY: Springer; 2010. 
9. Eustatia-Rutten CF, Corssmit EP, Biermasz NR, Pereira AM, Romijn JA, Smit JW. Survival and death causes in differentiated thyroid carcinoma. J Clin Endocrinol Metab. 2006;91:313-319.

10. Schlumberger M, Berg G, Cohen O, et al. Follow-up of low-risk patients with differentiated thyroid carcinoma: a European perspective. Eur $J$ Endocrinol. 2004;150:105-112.

11. Mazzaferri EL, Robbins RJ, Spencer CA, et al. A consensus report of the role of serum thyroglobulin as a monitoring method for low-risk patients with papillary thyroid carcinoma. J Clin Endocrinol Metab. 2003;88:1433-1441.

12. Verburg FA, de Keizer B, de Klerk JM, Lentjes EG, Lips CJ, van Isselt JW. Value of diagnostic radioiodine scintigraphy and thyroglobulin measurements after rhTSH injection. Nuklearmedizin. 2009;48:26-29.

13. Huang SH, Wang PW, Huang YE, et al. Sequential follow-up of serum thyroglobulin and whole body scan in thyroid cancer patients without initial metastasis. Thyroid. 2006;16:1273-1278.

14. Cailleux AF, Baudin E, Travagli JP, Ricard M, Schlumberger M. Is diagnostic iodine-131 scanning useful after total thyroid ablation for differentiated thyroid cancer? J Clin Endocrinol Metab. 2000;85:175-178.

15. Pacini F, Capezzone M, Elisei R, Ceccarelli C, Taddei D, Pinchera A. Diagnostic 131-iodine whole-body scan may be avoided in thyroid cancer patients who have undetectable stimulated serum Tg levels after initial treatment. J Clin Endocrinol Metab. 2002;87:1499-1501.

16. Taylor H, Hyer S, Vini L, Pratt B, Cook G, Harmer C. Diagnostic ${ }^{131}$ I whole body scanning after thyroidectomy and ablation for differentiated thyroid cancer. Eur J Endocrinol. 2004;150:649-653.

17. David A, Blotta A, Bondanelli M, et al. Serum thyroglobulin concentrations and ${ }^{131}$ I whole-body scan results in patients with differentiated thyroid carcinoma after administration of recombinant human thyroid-stimulating hormone. $\mathrm{J} \mathrm{Nucl}$ Med. 2001;42:1470-1475.

18. Robbins RJ, Chon JT, Fleisher M, Larson SM, Tuttle RM. Is the serum thyroglobulin response to recombinant human thyrotropin sufficient, by itself, to monitor for residual thyroid carcinoma? J Clin Endocrinol Metab. 2002;87: 3242-3247.

19. Spencer CA, Takeuchi M, Kazarosyan M, et al. Serum thyroglobulin autoantibodies: prevalence, influence on serum thyroglobulin measurement, and prognostic significance in patients with differentiated thyroid carcinoma. J Clin Endocrinol Metab. 1998;83:1121-1127.

20. Ma C, Kuang A, Xie J. Radioiodine therapy for differentiated thyroid carcinoma with thyroglobulin positive and radioactive iodine negative metastases. Cochrane Database Syst Rev. 2009;(1):CD006988. 